УДК 81.367.4

ББК 81.432.1

DOI: https://doi.org/10.17308/lic.2020.1/2733

\title{
ФРАЗЕОЛОГИЧЕСКИЕ И СЕНТЕНЦИОНАЛЬНЫЕ АТРИБУТЫ В СОВРЕМЕННОМ АНГЛИЙСКОМ ЯЗЫКЕ
}

\author{
Н. И. Овчинникова
}

Воронежский государственный университет

\section{PHRASE AND SENTENCE PREMODIFIERS IN MODERN ENGLISH}

\author{
N. I. Ovchinnikova \\ Voronezh State University
}

\begin{abstract}
Аннотация: настоящая работа посвящена изучению фразеологических и сентенциональных атрибутов, которые представляют сравнительно новое и малоизученное явление в английском языке. Их использование демонстрирует современные тенденции в развитии языка, такие как стремление к экономичной экспрессии и эмоционально маркированному описанию ситуации. Изучаемые сложные синтаксические конструкиии со спеичфическим графическим оформлением на письме являются своеобразными единицами косвенной номинации признака, отражающими индивидуальное, субъективно-эмоциональное восприятие предметов и ситуаций. На материале корпусных данных, полученных из современной художественной литературы на английском языке, выявляются способы осложнения премодификационных сочетаний, когда атрибутивную функиию выполняют словосочетание или иелое предложение. В ходе исследования анализируются основные структурно-семантические и комбинаторные особенности рассматриваемых конструкиий. Доминируюшим типом являются фразеологические атрибуты, компоненты которых связаны сочинительной связью и реализуют синонимичные или антонимичные отнотения. Они обладают разной степенью устойчивости и могут быть фиксированными и грамматически свободными, выражающими оригинальный предмет авторской мысли. Количество контекстов с сентенциональными атрибутами значительно уступает количеству фразео-атрибутивных словосочетаний. Показано, что они представляют некий аналог прямой речи персонажа и дают автору возможность более точно и экспрессивно передать чувства героя, поскольку для оченки эмоционального состояния в описание вводятся воображаемые слова человека.
\end{abstract}

Ключевые слова: фразеологические атрибуты, сентенциональные атрибуты, премодификационные словосочетания, сочинительные и подчинительные словосочетания, биномы.

Abstract: this paper is devoted to the study of phrase and sentence attributes, which represent a relatively new phenomenon in modern English and have not been thoroughly analysed. Their use demonstrates current trends in language development, such as the desire for economical expression and emotionally marked description of the situation. The studied complex syntactic constructions with nonstandard spelling are peculiar units of indirect nomination of a characteristic, reflecting the individual, subjective emotional perception of objects and situations. The corpus data obtained from modern English fiction reveals the ways to complicate premodifying combinations when the attributive function is performed by phrases or even sentences. In the course of the study, the main structural-semantic properties and combinatory features of the constructions under consideration are studied. The dominant type is coordinative phrase premodifiers, which realize synonymous or antonymous relations. They have various degrees of stability and can be fixed and grammatically free, expressing the author's attitude towards the subject. The number of contexts with sentence premodifiers is significantly inferior to the number of phrase attributes. It is shown that they represent a certain analogue of the character's direct speech and allow the author to convey the feelings of the hero more accurately and expressively, since imaginary words of a person are introduced into the description of the emotional state.

Key words: phrase attributes, sentence premodifiers, premodifying phrases, coordinate and subordinate phrases, binominals.

(с) Овчинникова Н. И., 2020 
Современный английский язык стремится к экономии языковых средств, и эта тенденция охватывает не только лексический, но и синтаксический уровни. Он является высоковалентным, поэтому элементы языка с легкостью могут вступать в разнообразные связи друг с другом. Стараясь подобрать наиболее точные и емкие средства выражения смыслов, говорящий избегает длинных фраз, предпочитая им более компактные синтаксические структуры.

Ярким примером подобных тенденций развития современного английского языка являются рассматриваемые в данной работе атрибутивные словосочетания, где в функции препозитивного определения выступает словосочетание и даже целое предложение, или так называемые дефисные композиты: Their dayafter-day complaints; She said it in a I-will-misshanging-out-with-you manner. Они представляют собой максимально сжатые и неделимые лексико-грамматические комплексы с особым графическим написанием через дефис, «спрессованные» в одно смысловое целое. Как отмечают авторы отечественных грамматик английского языка, в условиях препозитивного замыкания определения между детерминативом и существительным создаются возможности для использования широкого спектра средств модификации имени, вплоть до предикативных единиц, «стянутых» в слово [1, с. 201]. Употребление таких эмоционально-маркированных структур нашло отражение в устном разговорном языке, хотя они и плохо различимы на слух, так как не обладают особым интонационным рисунком. Атрибутивные дефисные композиты стали широко использоваться авторами современных художественных произведений для передачи индивидуальных особенностей персонажа, лаконичного уточнения разнообразных оттенков значений. Они также характерны для новостного дискурса, поскольку апеллируют к образным ассоциациям и способны к небанальному отражению ситуации, что свойственно, например, масс-медийному дискурсу по предвыборной тематике: Do-or-die moment for Republicans [2, с. 146].

Материалом настоящего исследования послужили контексты в количестве 500 единиц, собранные из произведений современной англоязычной художественной литературы. Изучаемые сложные синтаксические конструкции со специфическим графическим оформлением на письме являются своеобразными единицами номинации, отражающими индивидуальное, субъективно-эмоциональное восприятие предметов, событий, ситуаций и их качеств. Они служат средством косвенной номинации признака, являющимся непрямым, опосредованным выражением содержательных звеньев предложения, например, в русском языке: Принеси чем отрезать (нож, ножницы) $[3$, c. 64]. Особый интерес для изучения представляют разнообразные оттенки значений, которые несут в себе сложные структуры, стянутые в одно слово. Английские грамматисты отмечают, что они могут служить для выражения шутливо-ироничного отношения автора к своему герою или ко всей ситуации (have an air of the outrageous and improvised): He was being the boss again, using the it's-my-money-now-doas-you-are-told voice; или презрительного отношения: Miss what's-her-name [4, p. 1337].

Премодификационные сочетания являются особым «экологически чистым» языковым механизмом, где проявляется творчество носителей языка, стремление в одной лексической единице глубинно и многосторонне описать явления окружающей действительности. Вполне ожидаемо, что такие возможности не в полной мере осваиваются неносителями языка, хотя и в русском языке тенденция к употреблению сложных определительных конструкций с написанием через дефис проявляется все чаще: Чуть ли не половину мастерской занимал невероятный, обеденно-рабоче-раскройно-чертежный стол, на котором и за которым у обитателей этого дома была сосредоточена изрядная часть жизни [5].

При изучении атрибутивных сочетаний перед исследователем остро встает вопрос о трудности перевода подобных структур. Основная проблема заключается в том, как доподлинно передать смысл определения, сохранив оттенок разговорности и многообразие компонентов, входящих в его состав. Если с переводом таких простых определений, как комбинация «существительное + существительное», трудностей практически не возникает, то процесс перевода стянутых словосочетаний или предложений на русский язык вызывает сложности, например: He is a quick-to-take-offence man - Он человек, который легко обижается; set-the-Thames-afire gentlemen - Господа, которые хотят удивить мир. Перевод подобных структур на русский язык довольно часто осуществляется путем введения придаточного определительного. Корректный описательный перевод зачастую не имеет формальной близости с оригиналом, однако в целом он создает определенную степень эквивалентности, раскрывает информативное содержание специфических национальных конструкций.

Полученные в результате данного исследования контексты можно условно разделить на две неравновеликие группы: фразеосочетания (90 \% единиц) и стянутые предложения (10\% единиц) в атрибутивной позиции.

В рамках первой группы примеров компоненты словосочетаний в функции препозитивного определения реализуют два типа синтаксической связи и могут быть подразделены на сочинительные (55 \% единиц) и подчинительные (45 \% единиц). 
Элементы сочинительных словосочетаний традиционно связаны сочинительными союзами and, or или but. В рамках сочинительных сочетаний были обнаружены фразеоатрибуты с разной степенью устойчивости: фиксированные и грамматически свободные, являющиеся оригинальным предметом авторской мысли. Компоненты подобных словосочетаний могут реализовывать синонимичные или антонимичные отношения. Доминирующим типом фразеоатрибутов являются коллокации, т. е. лексически неделимые, устойчивые в своем составе и структуре, целостные по значению словосочетания, воспроизводимые в виде готовых речевых единиц. Лексическое значение таких словосочетаний, равно как и особое графическое оформление с написанием через дефис, закрепилось в словарях и стало языковой нормой: $\boldsymbol{a}$ black-and-white photograph, film; It was definitely going to happen, one of those sooner-or-later events. Такие устойчивые сочетания называются лингвистами по-разному: фразеологическими биномами [6, p. 233] или «сиамскими близнецами» [7, с. 92].

Первое место по частотности употребления занимают конструкции, состоящие из лексических синонимов, двух полнозначных слов со сходной семантикой, связанных сочинительным союзом and. Они, как правило, переводятся на русский язык либо простым определением: The wink-and-handshake deal-устная договоренность; либо синонимичными прилагательными: She had some kind of shabby-and-worn-out clothes on - потертая и изношенная одежда.

Интересна группа биномов, компоненты которых связаны антонимичными отношениями. Находясь в одной стяжательной конструкции, они представляют собой единое целое, но имеют противоположное значение и выражают разделительные или противительные отношения: That was a life-or-death attemptчрезвычайно отчаянная попытка; I said an unbelievable-but-true thing - нечто невероятное, но правдивое.

Среди проанализированных примеров частотны биномы, построенные по принципу аллитерации, придающей сочетанию особую звуковую выразительность, в основном с антонимичным значением элементов: It was not a routine, dusk-and-dawn talk of trusted relationship; I felt the fight-or-flight reflex. B данных контекстах повторение согласных звуков [d] или [f] придает словосочетаниям особое звучание и экспрессию. Подобные сочетания-повторы усилительного характера на основе аллитерации или ассонанса встречаются и в русской разговорной традиции, например, всем известные выражения «фокус-покус», «тяп-ляп», «умница-разумница».

Подчинительные фразеоатрибуты можно классифицировать, опираясь на следующие критерии: 1) по ядерному элементу словосочетания (субстантивные, глагольные, адъективные, адвербиальные и предложные словосочетания); 2) по степени слияния компонентов словосочетания (свободные и фразеологически несвободные словосочетания).

Подавляющее большинство подчинительных словосочетаний является субстантивными (64 \% контекстов) и представляют комбинацию noun-ofnоun. Кроме того, большинство таких словосочетаний фразеологизированы: word-of-mouth news - неподтвержденная информация, слухи, a spur-of-themoment thing - спонтанное решение.

Интересны подчинительные адъективные словосочетания, которые составляют сравнительно небольшую (15 \% контекстов), но разнообразную по формам группу. Фразеосочетания могут формироваться прилагательными в положительной степени с предложным дополнением: ready-to-eat chicken dishes, а также прилагательными в сравнительной степени в рамках сравнительного оборота с оценочной семантикой: Не was one of those larger-than-life figures.

Фразеоатрибуты, как правило, вводят разнообразные характеристики внешнего вида (улыбка, выражение лица), голоса, поведения, манер персонажа и преимущественно имеют в правостороннем окружении существительные look - взгляд и face expression - выражение лица. He gave her a naughty-boy lookавтор передает семантику вызова, дерзости, используя уже имеющийся в сознании читателя образ «naughty boy».

Премодификационные сочетания с использованием целого предложения - менее частотное, но интереснейшее явление в современном английском языке. И если фразеоатрибуты в большинстве своем представляют устойчивые сочетания слов, ставшие общеупотребительными, то для сентенциональных атрибутов характерен более разговорный, сленговый оттенок. Такие предложения являются предметом авторской мысли и могут противоречить установленным языковым нормам как в лексическом, так и в грамматическом плане, сохраняя при этом свой уникальный, иногда ироничный, выразительный характер. Однако в последнее время, по свидетельству Р. Кверка, некоторые из сочетаний становятся настолько частотными в употреблении, что переходят в разряд фразеологически устойчивых. Например, do-it-yourself shop (DIY) - сделай сам, утратило свой оригинальный оттенок и стало общепринятым [4, p. 1338].

Число собранных примеров с сентенциональными атрибутами (10 \% случаев) значительно уступает количеству фразеоатрибутивных словосочетаний. В результате анализа подобных структур было выявлено, что они представляют некий аналог прямой речи персонажа. Это позволяет автору более точно и экспрессивно передать чувства героя, поскольку для 
оценки эмоционального состояния в описание вводятся воображаемые слова человека. В позиции субъекта рассматриваемых конструкций, как правило, используется личное местоимение 1-го лица: I have a nasty churning in my stomach. That kind of I-don'twant-to-go-to-school sensation - такое чувство, что я не хочу идти в школу.

Собранные сентенциональные атрибуты можно подразделить по цели высказывания. Наиболее частотными из рассмотренных контекстов являются утвердительные предложения (81 \% примеров). We made an odd couple-with long well's pressed and pleated khaki pants and my I-keep-meaning-to-do-laundry blue jeans. Императивные предложения с семантикой побуждения к какому-либо действию, просьбы или приказа, а также вопросительные предложения гораздо менее распространены: He paused and looked at him with stop-playing-tricks-with-me look; How-didyou-know-that voice.

В изучаемых конструкциях могут быть выражены различные модальные оттенки значений, например, возможности/невозможности: I couldn't handle her I-can't-make-my-daughter's-dreams-come-true sad face; или уверенности/неуверенности: His progressive the-young-must-be-right attitude.

Изучаемые сентенциальные атрибуты характеризуют взгляд, выражение лица, голос, манеры и чувства человека, и в своем правостороннем окружении зачастую имеют лексемы - look, voice, manner. She still has that don't-you-touch-me look; Don't-ague-with-me voice. Интересно, что в препозиции таких композитов в основном используются детерминанты существительных - указательные и притяжательные местоимения that, her, his, указывающие на то, что такая манера поведения характерна для персонажа: The girl was wearing her nothing-really-matters face - ее типично безразличное выражение лица.

Таким образом, изучение фразеологических и сентенциональных атрибутов в английском языке может дать более глубокое понимание современных динамических тенденций в области синтаксиса, peaлизующихся в процессе речевой деятельности говорящего или пишущего.

\section{ЛИТЕРАТУРА}

1. Иванова И. П., Бурлакова В. В., Почепияов Г. Г. Теоретическая грамматика современного английского языка : учебник для студентов институтов и факультетов иностранных языков. М. : Высшая школа, 1981. 285 с.

2. Николаева О. В. Прагматический потенциал атрибутивных композитов в американском масс-медийном дискурсе по предвыборной тематике // Филологи- ческие науки. Вопросы теории и практики. Тамбов, 2016. № 9 (63) : в 3 ч. Ч. 3. С. 146-149.

3. Ломов $A$. M. Типология русского предложения. Воронеж : Изд-во ВГУ, 1994. 280 с.

4. Quirk R., Greenbaum S., Leech G., Svartvik J. A Comprehensive Grammar of the English Language. New York : Longman Inc., 1985. 1779 p.

5. Чекулаева T. A. Атрибутивные конструкции с внутренней предикацией в современном английском языке. URL: http://www.rusnauka.com/10_NPE_2009/ Philologia/43964.doc.htm

6. Benor S. B., Levy R. The Chicken or the Egg? A Probabilistic Analysis of English Binomials // Language 82. Edinburgh : University of Edinburgh, 2006. Pp. 233278.

7. Лукьянченко E. А. Феномен фразеологических биномов в английском языке и их передача на русский язык // Филологические науки в МГИМО. М., 2011. № 45 (60). С. 92-94.

\section{REFERENCES}

1. Ivanova I. P., Burlakova V. V., Pocheptsov G. G. Teoreticheskaya grammatika sovremennogo anglijskogo yazyka: uchebnik dlya studentov institutov i fakul'tetov inostrannykh yazykov [Theoretical grammar of modern English: textbook for students of institutes and faculties of foreign languages]. Moscow: Vysshaya shkola, 1981. 285 p.

2. Nikolaeva O. V. Pragmaticheskij potentsial atributivnykh kompozitov $v$ amerikanskom mass-medijnom diskurse po predvybornoj tematike [Pragmatic potential of attributive composites in the American mass media discourse on electoral topics]. Filologicheskie nauki. Voprosy teorii $i$ praktiki. Tambov: Gramota, 2016. № 9 (63). Part 3. Pp. 146149.

3. Lomov A. M. Tipologiya russkogo predlozheniya [Typology of Russian sentences]. Voronezh: Izdatelstvo VSU, 1994. 280 p.

4. Quirk R. A Comprehensive Grammar of the English Language. New York: Longman Inc., 1985. 1779 p.

5. Chekulaeva T. A. Atributivnye konstruktsii s vnutrennej predikatsiej $v$ sovremennom anglijskom yazyke [Attributive constructions with inner predication in modern English]. Available at: http://www.rusnauka.com/10 NPE_2009/Philologia/43964.doc.htm

6. Benor S. B., Levy R. The Chicken or the Egg? A Probabilistic Analysis of English Binomials. Language 82. Edinburgh: University of Edinburgh, 2006. Pp. 233-278.

7. Luk'yanchenko E. A. Fenomen frazeologicheskikh binomov $v$ anglijskom yazyke $i$ ikh peredacha na russkij yazyk [The phenomenon of phraseological binomials in the English language and their transfer to the Russian language]. Filologicheskie nauki v MGIMO. № 45 (60). Moscow: MGIMO-Universitet, 2011. Pp. 92-94. 
Воронежский государственный университет

Овчинникова Н. И., кандидат филологических наук, доцент кафедры английской филологии

E-mail:nata_o@inbox.ru

Поступила в редакцию 16 сентября 2019 г.

Принята к публикаичи 27 декабря 2019 г.

\section{Для цитирования:}

Овчинникова Н. И. Фразеологические и сентенциональные атрибуты в современном английском языке // Вестник Воронежского государственного университета. Серия: Лингвистика и межкультурная коммуникация. 2020. № 1. C. 77-81. DOI: https://doi. org/10.17308/lic.2020.1/2733
Voronezh State University

Ovchinnikova N. I., Candidate of Philology, Associate Professor of the English Philology Department

E-mail: nata_o@inbox.ru

Received: 16 September 2019

Accepted: 27 December 2019

\section{For citation:}

Ovchinnikova N. I. Phrase and sentence premodifiers in modern English. Proceedings of Voronezh State University. Series: Linguistics and Intercultural Communication. 2020. No. 1. Pp. 77-81. DOI: https:// doi.org/10.17308/lic.2020.1/2733 